\title{
Belajar Pilkada Bersama Pelajar Disabilitas SLBN 1 Bantul DIY
}

\author{
King Faisal Sulaiman, Nasrullah \\ Program Studi Hukum, Fakultas Hukum Universitas Muhammadiyah Yogyakarta \\ Jl. Lingkar Selatan, Tamantirto, Kasihan, Bantul, Yogyakarta, 55183 \\ email: kingfaisalumy@gmail.com \\ DOI: 10.18196/ppm.37.267
}

\begin{abstract}
Abstrak
Pendidikan politik Pilkada bagi kelompok pelajar disabilitas merupakan hak asasi yang dijamin konstitusi namun dalam praktik, tidak mudah diwujudkan. Topik ini dipilih untuk mengantisipasi agenda pemilihan kepala daerah (Pilkada) Bantul pada 2020. Guna mewujudkan Pilkada yang jujur, berkualitas, dan berkeadilan. Program ini akan memberikan penguatan kapasitas hak-hak politik kepemiluan bagi pelajar disabilitas kelompok pemilih pemula di SLBN 1 Bantul, selaku kelompok sasaran penerima manfaat. Program ini diarahkan untuk: (1) memberikan pemahaman hak-hak politik Pilkada, (2) kemampuan mengadvokasi diri, membangun posisi tawar, dan kesadaran politik dikalangan pelajar disabilitas (pemilih pemula) terkait hak-hak kepemiluannya dalam Pilkada. Metode kegiatan berupa penyuluhan hukum Pilkada, diskusi non formal disertai simulasi/role playing contoh kasus aktual dan kontekstual terkait edukasi hak-hak politik dalam Pilkada. Diharapkan program ini memberikan kontribusi signifikan bagi kualitas demokrasi berupa peningkatan pengetahuan, kemampuan mengadvokasi diri, membangun posisi tawar, dan kesadaran politik guna turut mensukseskan Pilkada Bantul 2020 serta bisa menjadi pilot project bagi kegiatan serupa terutama di Daerah Istimewa Yogykarta.
\end{abstract}

Kata kunci: Pelajar Disabilitas, Hak Politik, Pemilih Pemula, Pilkada Bantul 2020.

\section{Pendahuluan}

Program "Sinau Pilkada", merupakan bentuk edukasi politik yang mencerahkan bagi kalangan pelajar disabilitas agar mereka mampu mengedukasi dirinya sendiri, menggunakan hak politik/hak suaranya dengan tepat dan tidak mudah terkooptasi dalam menentukan kandidat pilihan politiknya. Partisipasi politik kelompok ini seringkali diragukan dan bahkan dipandang tidak legitimate dan eligble untuk menentukan calon pemimpin Kepala Daerah (Adinda, 2010; Hendriani Wiwin,2012). Padahal konstitusi telah menjamin, hak dipilih dan memilih dalam pemilu (Pilkada) merupakan hak kelompok disabilitas yang tidak dapat dikurangi dalam bentuk apapun (Salim Ishak, 2018; Perludem, 2015). Bantul adalah Kabupaten dengan angka penyandang disabilitas, tertinggi kedua setelah kabupaten Gunung Kidul di D.I Yogyakarta (Data BPS DIY; 2019).

Pada Pilkada Bantul 2015, angka partisipasi politik oleh pelajar disabilitas selaku pemilih pemula masih sangat minim (Data KPU Bantul; 2015). Salah satu penyebabnya adalah minimnya pengetahuan dan sosialisasi hak-hak politik (political rights), sebagaimana hasil studi pendahuluan dikalangan pelajar disabilitas di SLBN 1 Bantul DIY. Dari total 323 pelajar, sebanyak 96 pelajar terkategori pemilih pemula yang juga kelompok swing voter atau floating mass, sehingga hak-hak politiknya rawan disalahgunakan (data per Desember 2019). Alasannya cukup beragam, mulai dari faktor saling percaya karena hubungan darah/keluarga atau pertemenan sehinga kelompok pelajar disabiltas ini dengan mudah mempercayakan begitu saja penggunaan hak politik (hak suara) dalam memilih kandidat tertentu tanpa disortir terlebih dahulu.

Mereka juga tidak mampu mengidentifikasikan permasalahan dihadapinya di lapangan (Masduqi, 2010), setidaknya mencakup; (1) sepertia apa; kemana menjatuhkan pilihan politik/menggunakan hak suaranya; (2) apakah konstitusi, UU Pilkada, UU Penyandang 
Disabilitas menjamin hak-hak politik kaum difabel (setara dengan pemilih non difabel); (3) apakah ada perlakuan privellege/fasilitas khusus dari KPUD untuk kelompok disabilitias; dan (4) bagaimana mencari tahu/mengetahui visi-misi/track record sang kandidat agar tidak salah pilih; (5) bagaimana mengajukan keberatan/komplain atas pelanggaran hak-hak kepemiluan yang terjadi; dan termasuk (6) perlakuan tidak adil dari lembaga penyelenggara Pilkada.

Tidak jarang orang normal yang mendampinginya untuk mencoblos di TPS, justru memanipulasi hak politik dengan memberikan informasi/rekam jejak yang sesat dan bahkan secara sepihak mengarahkan si pemilik hak suara (difabel) menggunakan hak politiknya (Syarif Ibnu Mujar, 2017). Program ini akan mengedukasi pelajar disabilitas di SLBN 1 bantul dengan sejumlah materi pengayaan yang mencakup; (1) hak-hak politik/political rights yang dijamin UUD, UU Pemilu/Pilkada, PKPU/regulasi terkait; (2) mensimulasikan tahapan partisipasi politik difabel dalam pilkada, (3) bagaimana mereka memastikan diri tercatat dalam DPT/mendapatkan Suket, (4) bagaimana mengorganisir diri untuk datang ke TPS/TPS dan; (5) memilih jenis kartu suara khusus difabel/cara mencoblos/menggunakannya. Progran ini juga menjadi media untuk mendengar aspriasi dan membangun kesadaran politik pelajar difabel, termasuk pentingnya mengkaver jejak rekam/visi-misi para kandidat Bupati. SLBN 1 Bantul mempunyai reputasi SLB terbaik di DIY, tingkat nasional dan pernah terbaik se-Asia Tenggara pada 2014. Oleh karenanya, program diharapkan bisa menjadi pilot project dalam kegiatan serupa terutama di Daerah Istimewa Yogyakarta.

\section{Metode Pelaksanaan}

Tempat dan Waktu

Lokasi pengabdian kemitraan ini dilaksanakan di SLBN 1 Bantul Yogyakarta dan berlangsung selama tiga bulan yakni dari Januari, Februari dan Maret 2019

\section{Khalayak Sasaran}

Target sasaran penerima manfaat adalah pelajar penyandang disabilitas/difabel di SLBN 1 Bantul yang merupakan pemilih pemula yang rawan dipolitisasi hak-hak politiknya dalam Pilkada. Kelompok ini terindetifiaksi sebagai: (a) massa mengambang/floating mass/swingg voter dan (b) sudah memiliki hak pilih, akan tetapi (c) masih mempunyai pengetahuan/kapasitas, kesadaran hukum pilkada yang terbatas. Mereka juga diasumsikan mempunyai posisi tawar poltik yang lemah, dan kemampuan mengadovkasi hak-hak politik yang terlanggar. Selain itu mereka juga memiliki kesadaran/partisipasi politik yang masih minim termasuk bagaimana mengajukan protes/aspirasi/tuntutan kepada penyelenggara pemilu (KPUD/Bawaslu). Kegiatan ini dilaksanakan dengan tahapan sebagai berikut :

1. Tahap Awal Persiapan. Tim melakukan kordinasi dan komunikasi dengan kelompok sasaran untuk memastikan terselenggaranya kegiatan pengabdian dimaksud sesuai target. Tim melakukan rangkaian rapat/meeting koordinasi teknis internal termasuk perumusan metedologi kegiatan

2. Identifikasi Masalah. Mencakup bagaimana pola hubungan antara kelompok sasaran dengan penyelenggara pilkada (KPUD/Bawaslu), bagaimana bentuk pendidikan pemilih pemula yang mereka terima selama ini. 
3. Studi Dokumen Hukum. Berupa studi atas sejumlah produk hukum relevan, secara komprehensif diantaranya UUD 1945-, UU Pilakada/Pemilu, UU Penyandang Disiabiltias, UU Penyelenggara Pemilu, PKPU/regulasi yang terkait.

4. Identifikasi Calon Partisipan. Mencakup, pelajar disablitais yang (a) paling terlanggar haknya, (b) bentuk pelanggaran hak; (c) pelaku pelanggaran; (d) apakah mereka tahu cara menyampaikan keberatan/menyelesaikan persoalan; dan (e) apakah mereka pernah menyampaikan keberatan ketika mendapat perlakukan yang tidak semestinya.

5. Penyuluhan Hukum Pilkada. Dikemas dalam suasan dialog yang interaktif pada kelompok sasaran sebanyak satu kali/satu hari. Narasumber dari penyelenggara Pemilu (KPUD/Bawaslu) dan akademisi.

6. Diksusi Non Formal dan Simulasi/Role Playing Pelanggaran Pilkada. Lebih ditujukan untuk mengeksplorasi kemampuan diri partisipan dan bagaimana menurut mereka mengembangkan kemampuan diri tersebut. Naramber/fasilitator kegiatan mencakup penyelenggara pilkada, akademsi/praktisi.

7. Monitoring dan Evaluasi. Dilaksanakan secara aktif-partisipatoris. Setiap akhir kegiatan partisipan diminta menjawab sejumlah pertanyaan tertulis yang diajukan pelaksana. Stakeholders yang terlibat sebisa mungkin dilibatkan dalam monitoring dan evaluasi.

8. Keberlanjutan. Diharapkan program ini memberikan kontribusi signifikan bagi kualitas demokrasi Pilkada Bantul 2020 serta bisa menjadi pilot project bagi kegiatan serupa terutama di Daerah Istimewa Yogykarta.

9. Manejemen dan Akuntabilitas Program. Pendidtribusian beban dan tanggungjwab kerja dilakukan sesuai jenis kegiatan, artinya tidak berdasarkan permasalahan/isu yang teridentifikasi. Beban pencapaian dalam pengabdian ini akan didistribusikan kepada Tiim eksekusi program yang menangani satu kegiatan/program dengan dukungan tim kerja yang solid.

\section{Hasil dan Pembahasan}

1. Penyuluhan Hukum Pilkada

Program ini dilaksanakan langsung oleh Tim Pengabdi sendiri, terbagi menjadi dua sesi. Sesi pertama, bertempat di Aula SLBN 1 Bantul Yogyakarta. Adapun narasumber pertama disampaikan oleh Dr. King Faisal Sulaiman S.H., LL.M, dengan topik: Praktek Politik Uang (Money Politics) dan dampaknya bagi kualitas pilkada. Kegiatan dihadiri oleh sejumlah partisipan yang teridentifikasi selaku pemilih pemula (pelajar disabalitas). Para partisipan cukup proaktif, dan terlibat dalam rangkaian diskusi dengan alur tanya jawab dalam suasana santai. Waktu yang disediakan untuk mengajukan pertanyaan dan dialog interaktif cukup maksimal dan santai sehingga para partisipan bisa langsung mengajukan pertanyaan sekalipun materi masih berlangsung. Desain waktu fleksibel ini, terbukti dengan tingginya antusias partisipan dalam mengajukan sejumlah pertanyaan terutama terkait: (a) seberapa penting para pelajar disabilitas wajib menggunakan hak suara/mencoblos; dan (b) kewajiban mengenal jejak rekam/trackrecord Kandidat Bupati dan Parpol pengusung dalam Pilkada Bantul 2020.

Pada sesi kedua, penyampaian materi penyuluhan hukum Pilkada masih tetap di Aula SLBN 1 Bantul DIY. Mendatangkan narasumber langsung dari komisioner KPUD Bantul yakni Mestri Widodo SIP, M.Si selaku ketua Divsi Hukum dan Pengawasan. Adpaun topik materi yanng 
disampaikan terkait beberapa aspek penting dalam UU Pilkada dan Pemilu. Terlihat semangat para partisipan sangat antusias mendengar ceramah yang disampaikan oleh pemateri. Dinamika forum juga kurang lebih sama dengan sesi pertama. Tingkat partisipasi para peserta cukup siginifikan, dengan mengajukan sejumlah pertanyaan terutama mencakup: (a) apa saja peran dan fungsi lembaga penyelenggara Pemilu/Pilkada (KPUD/Bawaslu); dan (b) hak-hak politik/political rights yang dijamin UUD, UU Pemilu/Pilkada, dan PKPU/regulasi terkait; kepemiluan.

\section{Diskusi Non Formal disertai Simulasi Pelanggaran Pilkada}

Kegiatan diskusi ini melibatkan dua narasumber yang berkompeten. Narasumber pertama, merupakan akademisi/aktivis Pilakda/Pemilu yang juga mantan Ketua KPUD Yogyakarta yakni Nasrullah SH. MCL. Adapun materi yang didiskusikan terkait "Tips Memilih Figur/Calon Kepala Daerah yang Pro Pelajar Disabilitas termasuk dampaknya bagi kualitas Pilkada. Kegiatan diskusi ini sebagai keberlanjutan dari kegiatan penyuluhan hukum Pilkada sebelumnya. Narasumber kedua berasal dari penyelenggara Pilkada sendiri yakni Nuril Hanif ST. selaku Komisioner Bawaslu Kabaputen Bantul. Topik diskusi yang disampaikan pemateri kedua titik tekannya lebih kepada peran KPU dan Bawaslu dalam penegakan pelanggaran pilkada.

Selain diskusi/suasana non formal, para partisipan juga diajak berpatrisipasi dalam permaian simulasi/role playing; yang mencakup antara lain: (a) siapa yang bersedia menajdi penyelenggara Pilkada/Komisioner termasuk (b) peran sebagai petugas TPS/PPK; disertai dengan (c) contoh/model praktik money politic/praktik pelanggagaran yang lazim terjadi. Pada prinspinya kegiatan kedua ini bertujuan untuk memperkuat pemahaman para pemilh pemula (pelajar disabilitas) sebagai partisipan, untuk lebih konkrit (a) model-model praktik money politic; dan (b) bagaimana cara kerja penyelenggar pemilu (KPUD/Bawaslu) dalam penegakkan hukum terkait pelanggaran pilkada yang terjadi. Muatan materi dalam kegiatan ini djuga disertai penjelasan contoh/kasus ilustrasi bagaimana praktik politik uang bekerja dengan berbagai modus operandi, termasuk dikalangan pelajar difabel selaku "swinger voter", pemilih pemula yang minus pengetahuan hak-hak kepemiuan dalam mewujudkan hasil Pilkada yang bereintegritas, pro kaum difabel dan rakyat.

Kegiatan masih dilaksanakan di aula SLBN 1 Bantul DIY dan dihadiri puluhan pemilih pemula (pelajar disabilitas) yang terlihat penuh semangat dan antusias untuk mengikuti berlangusngnya kegiatan. Para partsipan mensimulasikan; (a) bagaimana tahapan partisipasi politik difabel dalam pilkada, (b) bagaimana mereka memastikan diri tercatat dalam DPT/mendapatkan Suket, (b) bagaimana mengorganisir diri untuk datang ke TPS/TPS dan; (c) memilih jenis kartu suara khusus difabel/cara mencoblos/menggunakannya demi terciptanya pemilu yang sehat, berkualitas. Selain sejumlah poster dan buku terkait hak-hak kepemiluan/pilkada dibagikan gratis kepada para partisipan yang bertuliskan jargon agar pemilih pemula untuk tidak golput pada pemilu nanti dan agar menjadi pemilih pemula yang cerdas.

\section{Role Playing}

Kegiatan ini merupakan rangkaian dari agenda diskusi non formal. Sebagai upaya untuk mengenal secara langsung, hak-hak pilkada/kepemiluan. Partisipan, yang notabene merupakan 
pelajar terkategori pemilih pemula, diajak bermain peran. Untuk mensimulasikan/mempraktikkan dalam program ini, para pemilih pemula memainkan peran secara bergantian. Bagaiamana model-model praktik money politic dan bagaimana cara kerja penyelenggara pemilu (KPUD/Bawaslu) dalam penegakkan hukum terkait pelanggaran Pilkada yang terjadi.

Materi dalam "roley playing” ini juga disertai penjelasan contoh/kasus ilustrasi. Bagaimana praktik politik uang bekerja dengan berbagai modus operandi dan tahapan partisipasi politik difabel dalam pilkada. Partisipan juga memperagakan bagaimana memastikan diri tercatat dalam DPT atau mendapatkan Suket, termasuk kemampuan mengorganisir diri untuk datang ke TPS/TPS dan memilih jenis kartu suara khusus difabel/cara mencoblos. Para partisipan dibagai ke dalam beberapa kelompok kecil (small group). Lalu memainkan perannya sesuai dengan topik yang dipilih/diberikan oleh fasilitator. Tujuannya agar terselenggaranya pilkada jurdil dan berkualitas.

\section{Simpulan}

Pelanggaran dan pemenuhan hak-hak politik bagi pemilih pemula terlebih di kalangan pelajar disabilitas adalah salah satu titik yang paling bermasalah dalam pendidikan politik pilkada di Indonesia. Program "Sinau Pilkada" ini akan memberikan penguatan pendidikan politik bagi pemilih pemula di kalangan pelajar disabilitas terutama dalam menghadapi event Pilkada Bantul 2020. Program ini akan memberikan (a) pengetahuan; (b) kemampuan mengadvokasi diri; (c) membangun posisi tawar, dan; (d) kesadaran politik terkait hak-hak kepemiluan di kalangan pelajar disabilitas. Program ini sekaligus mengafirmasi dukungan penuh terwujudnya Pilkada Bantul 2020 yang jujur, bermartabat dan berkeadilan serta menghasilkan pemimpin yang demokratis dan prokepentingan kaum disabilitas. Diharapkan out put lanjutan dari program ini, bisa menjadi "pilot project" bagi program serupa di semua kabupaten/kota di DIY.

Penguatan kapasitas, sosialisasi dan advokasi hak-hak politik pilkada di kalangan pelajar difabel merupakan agenda bersama seluruh stakeholder. Penting bagi penyelenggara pemilu (KPUD/Bawaslu) untuk melibatkan akademisi/kampus sebagai mitra strategis. Demi mewujudkan Pilkada/Pemilu yang berkualtias dan berintegritas. Perlu ada program lanjutan yang berksinambungan dengan kelompok sasaran yang sama. Program ini, bisa ditindaklanjuti menjadi "pilot project" bagi program edukasi politik, yang pro pelajar disabilitas di semua Kabupaten/Kota di Daerah Isitmewa Yogyakarta. Para partispan diharapkan pula bertindak sebagai stimulator bagi kelompok pemilih pemula lainnya di DIY. Untuk turut mewujudkan pemimpin berkualitas melalui Pilkada yang jujur dan berintegritas.

\section{Ucapan Terima Kasih}

Penulis dalam pengabdian ini menyampaikan apresiasi dan terimakasih kepada Pihak Lembaga Pendidikan, Penelitian dan Pengabdian pada Masyarakat (LP3M) Universitas Muhammdiyah Yogyakarta sebagai pemberi dana hibah pengabdian Tahun 2020, Kepala Sekolah SLBN 1 Bantul D.I. Yogyakarta, para siswa/siswa partisipan, serta semua pihak lain terlibat dalam pengabdian ini. 


\section{Daftar Pustaka}

Buku dan Artikel:

Bisariyadi, et.al. (2012). Komparasi Mekanisme Penyelesaian Sengketa Pemilu di Beberapa

Negara Penganut Paham Demokrasi Konstitusional. Jurnal Konstitusi Volume 9, Nomor 3, September 2012.

David Bentham dan Kevin Boyle. (2000). Demokrasi. Yogyakarta: Kanisius.

Hayat, H. (2014). Korelasi Pemilu Serentak dengan Multi Partai Sederhana Sebagai Penguatan Sistem Presidensial. Jurnal Konstitusi, 11(3), 468-491.

Hanan, D. (2016). Memperkuat Presidensialisme Multipartai di Indonesia: Pemilu Serentak,

Sistem Pemilu dan Sistem Kepartaian. Jurnal Universitas Paramadina, 13, Hal. 1451-1475.

Janedjri M.Gaffar, 2012, Politik Hukum Pemilu, Jakarta, Konstitusi Press (Konpress), hlm. 29

Jimly Asshiddiqie, "Pengantar Ilmu Hukum Tatanegara",.(Jakarta: Rajagrafindo Persada,2009) hlm.416.

Kesi Widjajanti, Model Pemberdayaan Masyarakat, Jurnal Ekonomi Pembangunan Volume 12, Nomor 1, Juni 2011.

Khairul Fahmi, "Prinsip Kedaulatan Rakyat Dalam Penentuan Sistem Pemilihan Umum Legislatif'. Jurnal Konstitusi, Vol 7, Nomor 3, Juni 2010

Miriam Budiarjo, Dasar-Dasar ilmu Politik, Edisi Revisi, Jakarta : Gramedia Pustaka Utama, 2008,Hal 461.

Novembri Yusuf Simanjuntak, "Pemantauan Dalam Proses Penyelenggaraan Pemilu", Vol 3, Nomor 3, Tahun 2017.

Sri Hastuti P, "Pemilu Dan Demokrasi Telaah Terhadap Prasyarat Normatif Pemilu”, Jurnal Hukum, Vol 11, Nomor 25 Tahun 2004

Sitepu, P.A. (2012). Studi Ilmu Politik. Yogyakarta: Graha Ilmu.

Shubhan, H. (2006). Recall: Antara Hak Partai Politik dan Hak Berpolitik Anggota Parpol. Jurnal Konstitusi, 3(4), 3057.

Surbakti, R., Supriyanto, D., \& Asy'ari, H. (2011). Merancang Sistem Politik Demokratis Menuju Pemerintahan Presidensial yang Efektif. Jakarta: Kemitraan bagi Pembaruan Tata Pemerintahan.

Undang-Undang:

Undang-Undang No. 17 tahun 2017 tentang Pemilihan Umum.

Internet:

"Kemenkominfo: Ada 1000 Berita Hoax Selama Masa Kampanye Pemilu", diunduh dari ttps://news.detik.com/ berita/4264513/kemenkominfo-ada-1000-berita-hoax-selama-masakampanye-pemilu.www.kpu.go.id 